\title{
A ZVS PWM Three-Phase Inverter with Active Clamping Technique Using Only a Single Auxiliary Switch
}

\author{
DENIZAR CRUZ MARTINS, MARCELLO MEZAROBA, and IVO BARBI \\ Department of Electrical Engineering - Power Electronics Institute \\ Federal University of Santa Catarina \\ P.O. Box 5119, CEP 88040-970, Florianópolis, SC \\ BRAZIL
}

\begin{abstract}
This paper presents the analysis of a ZVS PWM Three-Phase Inverter with active voltage clamping technique using the reverse recovery energy of the diodes to improve the converter efficiency. The structure is particularly simple and robust. It is very attractive for Three Phase high power applications. Conduction and commutation losses are reduced due to implementation of a simple active snubber circuit that provides ZVS conditions for all switches, including the auxiliary one. Its main features are: Simple control strategy, robustness, lower weight and volume, lower harmonic distortion of the output current, and high efficiency. The operation principle for steady-state conditions, mathematical analysis and experimental results from a laboratory prototype are presented.
\end{abstract}

Key-Words: - Three-Phase Inverter, ZVS commutation, Active Clamping Technique.

\section{Introduction}

With the appearance of the Bipolar Transistors in the 50s and posteriori the Mosfets in the 80s, PWM modulation techniques could be used together with the increase of the commutation frequency, with the aim to reduce the harmonic distortion in the output of the nverters. These measures give some benefits like the reduction of the volume and weight of the filters and magnetic elements; nevertheless they cause some difficulties due to the high commutation losses in the switches, which reduce the converter efficiency, and the electromagnetic interference appearing. This event ocurs mainly in inverter topologies that use the bridge configuration; where the main switch conduction provoke the reverse recovery phenomenon of the anti-parallel diode of the complementary switch. A great number of works have been developed by power electronics scientific community, with the aim to diminish these problems. They can be divided in two groups: passive techniques $[6,7,8,9]$ and active techniques [1, 2,3 10, 11].

In the active techniques area, some researches were made recently using the reverse-recovery energy from the diodes to obtain soft commutation in the switches of the pre-regulated rectifiers with high power factor $[4,5]$. In this paper a ZVS PWM Three-Phase Inverter with voltage clamping across the switches, using only a single auxiliary switch, is presented. The proposed structure uses the diode reverse recovery energy technique to obtain soft commutation in all switches.

This topology presents some advantages in comparison with the conventional soft commutation inverters studied in the literature, which we can point out:

- Soft commutation in all load range;

- Simple topology with a low number of components;

- Use a classical PWM modulation;

- Auxiliary switch works with constant duty cycle in all operation stages;

- Use of slow and low cost rectifiers diodes;

- Low clamping voltage across the capacitor;

- Low current stress through the main switches;

- Simple design procedure with low restrictions;

- High efficiency. 


\section{Proposed Circuit}

The proposed circuit is shown in Fig. 1. It presents a Three-Phase inverter configuration, where Q1, Q2, Q3, Q4, Q5 and Q6 are the main switches, and Qa is the auxiliary switch. C1, C2, C3, C4, C5 and C6 are the commutation capacitors.

One controlled switch Qa, with anti-parallel diode Da, one small inductor Ls and one clamping capacitor Cs form the snubber circuit. The capacitor $\mathbf{C s}$ is responsible by the storage of the diode reverse recovery energy and by the clamping of switches voltage. The inductor $\mathbf{L s}$ is responsible by the control of the $\mathbf{d i} / \mathbf{d t}$ during the diode reverse recovery time. The auxiliary switch works with constant duty cycle in all operation stage. One of the most advantages of this converter consists in the use of only one auxiliary switch, which provides the clamping of the voltage and the ZVS conditions for all switches, including the auxiliary switch in the snubber circuit.

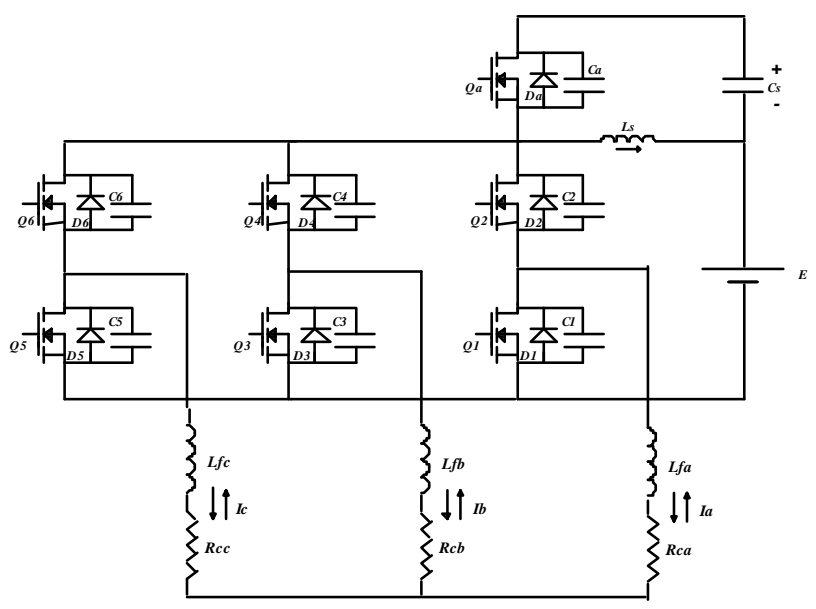

Fig. 1. Proposed Circuit.

\section{Operation Stages}

The inverter has symmetrical operation stages, so, will be presented the analysis to only one combination of the load currents. To simplify the studies, the following assumptions are made: the operation of the circuit is steady state; the semiconductors are considered ideal (excluding the reverse recovery of the diodes); the voltage across the capacitor $\mathbf{C s}$, and the current in the output inductors are considered constant during the switching period. The main waveforms are shown in Fig. 2 and Fig. 3 shows the main operation stages.

First stage (t0-t1): At this stage, the current Ia flows through the circuit formed by inductor Ls, source V1 and diode D5. The current Ib flows through the diode D4 and current Ic flows through the diode D2. At same time, the additional arrent iLs flows through Qa, Ls and Cs.

Second stage (t1-t2): This stage starts when the auxiliary switch Qa is blocked. The current iLs begins the charge of the capacitor Ca from zero to $\mathbf{E}+\mathbf{V} \mathbf{c s}$, and discharges $\mathbf{C 1}, \mathbf{C 3}$ and $\mathbf{C 6}$ from $\mathbf{E}+\mathrm{Ves}$ to zero.

Third stage (t2-t3): At this stage the voltage across C1, C3 and C6 reaches zero, and are clamping by the anti-parallel diodes D1, D3 and D6. So, the switches Q1, Q3 and Q6 conduct with ZVS condition. At this moment, the bus voltage $\mathbf{E}$ is applied across the inductor Ls and the current iLs decrease linearly.

Fourth stage (t3-t4): It begins when the current iLs inverts its direction and flows through the switches Q1, Q3 and Q6. The current iLs continues to decrease until inverting its direction of current of the diodes D2, D4 and D5, starting its reverse recovery phase. The inductor Ls limits the diLs/dt.

Fifth stage (t4-t5): This stage starts when the diodes D2, D4 and D5 finish its reverse recovery phase. The current iLs begins the charge of the capacitors C2, C4 and $\mathbf{C 5}$ from zero to $\mathbf{E}+\mathbf{V e s}$ and the discharge of $\mathbf{C a}$ from $\mathbf{E}+$ Ves to zero.

Sixth stage (t5-t6): At this stage the voltage across the capacitor Ca reaches zero, and it is clamped by the diode Da. Thus, the auxiliary switch Qa conducts with zero-voltage switching. The current iLs increases, due the application of the voltage Ves across the inductor Ls.

Seventh stage (t6-t7): This stage begins when the current iCs changes its direction and flows through the switch Qa. The current iLs continues to increase linearly.

Eighth stage (t7-t8): At this stage the switch $\mathbf{Q 1}$ is blocked. The capacitor $\mathbf{C 1}$ charges itself from zero to $\mathbf{E}$ + Ves and the capacitor C2 discharges itself from E + Ves to zero.

Ninth stage (t8-t9): It begins when the voltage across the capacitor $\mathbf{C 2}$ reaches zero, and it is clamped by the diode D2. The current iLs continues increasing.

Tenth stage (t9-t10): At this stage the switch Q3 is blocked. The capacitor $\mathbf{C 3}$ charges itself from zero to $\mathbf{E}$ + Ves and the capacitor $\mathbf{C 4}$ discharges itself from $\mathbf{E}+$ Ves to zero. 
Eleventh stage (t11-t12): It begins when the voltage across the capacitor $\mathbf{C 4}$ reaches zero, and it is clamped by the diode D4. The current iLs continues increasing.

Twelfth stage (t12-t0): At this stage the switch Q6 is blocked. The capacitor $\mathbf{C 6}$ charges itself from zero to $\mathbf{E}+$ Ves and the capacitor $\mathbf{C 5}$ discharges itself from $\mathbf{E}$ + Ves to zero. This stage finishes when the voltage across the capacitor $\mathbf{C 5}$ reaches zero, and it is clamped by the diode D5, restarting the first operation stage.

\section{Mathematical Analysis of the Soft- Switching Circuit}

To guarantee ZVS conditions, it is necessary, in the second stage, that the stored energy in the inductor Ls be sufficient to discharge the capacitor $\mathbf{C 1}, \mathbf{C 3}$ and $\mathbf{C 6}$ and to charge Ca. Thus, by inspection of Fig. 3 (Interval t1t2) the following condition can be formulated:

$$
L s I f^{2} \geq(C a+C 1+C 3+C 6)(V+V g)^{2}
$$

where If is the maximum current in Cs, and Ves is maintained constant during a switching period. Assuming Ves $<<$ E we have:

If $\min \geq E \sqrt{\frac{C a+C 1+C 3+C 6}{L s}}$

It is necessary to know the clamping voltage behavior for the design of the switches and capacitor Cs. In the steady state conditions the clamping capacitor average current must be zero. Thus:

$$
\begin{aligned}
& i C s_{a v i}=\frac{1}{T s}\left[\int_{0}^{t 7}\left(\frac{V c s}{L s} \cdot t-3 I r\right) d t+\int_{t 7}^{t 9}\left(\frac{V c s}{L s} \cdot t-3 I r-I c\right) d t+\right. \\
& \left.\int_{t 9}^{t 11}\left(\frac{V c s}{L s} \cdot t-3 I r-I c-I b\right) d t \int_{t 11}^{t 1}\left(\frac{V c s}{L s} \cdot t-3 I r-I c-I b-I a\right) d t\right]
\end{aligned}
$$

where Ts is the switching period.

Solving the integral equation, and considering:

$$
D 1=\frac{t 7}{T s} ; \quad D 3=\frac{t 9}{T s} ; \quad D 6=\frac{t 11}{T s} ; \quad t 1 \approx T s ;{ }_{i C s_{a v}}=0
$$

We have:

$$
V c s=\frac{2 L s}{T s}[3 \cdot I r+I a(2-D 1-D 6)+I b(D 1-D 3)]
$$

The output currents are given by:
$I a=\frac{E \cdot m a}{2 \cdot Z c a} \cdot \operatorname{sen} \omega t$

$I b=\frac{E \cdot m a}{2 \cdot Z c b} \cdot \operatorname{sen}\left(\omega t-\frac{2 \cdot \pi}{3}\right)$

$I c=\frac{E \cdot m a}{2 \cdot Z c c} \cdot \operatorname{sen}\left(\omega t-\frac{4 \cdot \pi}{3}\right)$

The load impedance are given by:

$$
\begin{aligned}
& Z c a=\sqrt{R c a^{2}+(\omega \cdot L c a)^{2}} \\
& Z c b=\sqrt{R c b^{2}+(\omega \cdot L c b)^{2}} \\
& Z c c=\sqrt{R c c^{2}+(\omega \cdot L c c)^{2}}
\end{aligned}
$$

$R c a, R c b$ e Rcc-Load resistances;

$L c a, L c b$ e Lcc - Load inductances

where $\boldsymbol{m} \boldsymbol{a}$ represents the modulation factor of amplitude.

The duty cycle $\boldsymbol{D}$ can also be defined as:

$$
D=m a \cdot \operatorname{sen} \omega t
$$

From Eqs. 5 and 12 we obtain the expression of the Vcs voltage.

$$
\begin{aligned}
& V c s(t)=\frac{2 \cdot L s}{T s}\left[3 \cdot I r+\frac{E \cdot m a}{Z c a} \cdot \operatorname{sen} \omega t-\frac{E \cdot m a^{2}}{2 \cdot Z c a} \cdot \operatorname{sen}^{2} \omega t-\frac{E \cdot m a^{2}}{2 \cdot Z c a} \cdot \operatorname{sen} \omega t \cdot \operatorname{sen}\left(\omega t-\frac{4 \cdot \pi}{3}\right)\right. \\
& \left.+\frac{E \cdot m a^{2}}{2 \cdot Z c b} \cdot \operatorname{sen} \omega t \cdot \operatorname{sen}\left(\omega t-\frac{2 \cdot \pi}{3}\right)-\frac{E \cdot m a^{2}}{2 \cdot Z c b} \cdot \operatorname{sen}^{2}\left(\omega t-\frac{2 \cdot \pi}{3}\right)\right]
\end{aligned}
$$

where $\boldsymbol{I r}$ is the peak reverse recovery current of the anti-parallel diode, which can be given by:

$I r=\sqrt{\frac{4}{3} \cdot Q r r \cdot \frac{E}{L s}}$

Qrr - Reverse Recovery Charge

From the analysis of the current behavior in the capacitor Cs, the expression of the current If can be obtained:

$$
I f(t)=\frac{V c s}{L s} \cdot T s-2 \cdot I a-3 \cdot I r
$$

Combining Eq. 13 with Eq. 15 and making some simplifications we obtain the expression that represents the evolution of the current If.

To guarantee ZVS condition in all load range the minimum value of the current If obtained from Eq. 16 must be bigger than the value obtained from Eq. 2 .

$$
\begin{aligned}
& \text { If }(t)=2 \cdot I r+\frac{E \cdot m a}{Z c a} \cdot \operatorname{sen} \omega t-\frac{E \cdot m a^{2}}{Z c a} \cdot \operatorname{sen}^{2} \omega t-\frac{E \cdot m a^{2}}{Z c a} \cdot \operatorname{sen} \omega t \cdot \operatorname{sen}\left(\omega t-\frac{4 \cdot \pi}{3}\right) \\
& +\frac{2}{E \cdot m a} \cdot \operatorname{sen} \omega t \cdot \operatorname{sen}\left(\omega t-\frac{\overline{2 \cdot \pi}}{-}{ }_{-} \frac{E^{2}}{-\cdot \cdot{ }^{2}} \cdot \operatorname{sen}^{2}(\omega t-\overline{2 \cdot \pi})\right.
\end{aligned}
$$


5. Design Example

5.1 Input Data

$\mathrm{E}=400 \mathrm{~V}$

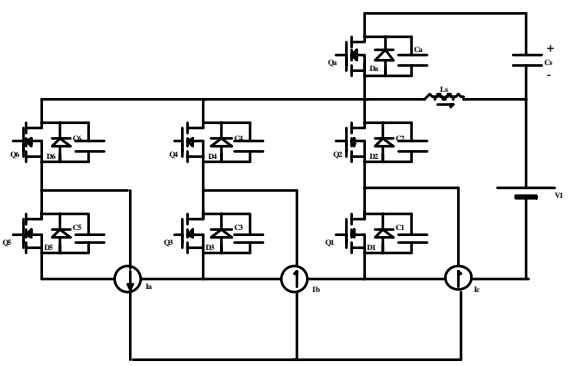

First stage (to-t1)
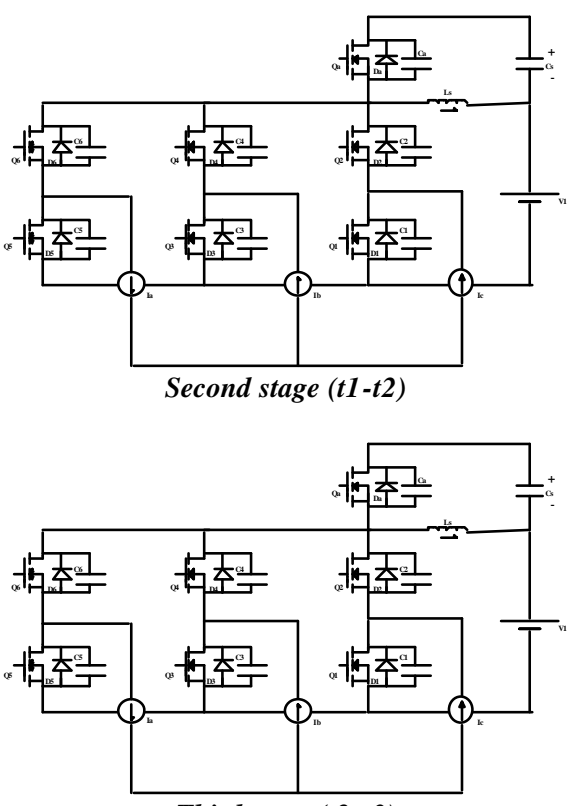

Third stage (t2-t3)

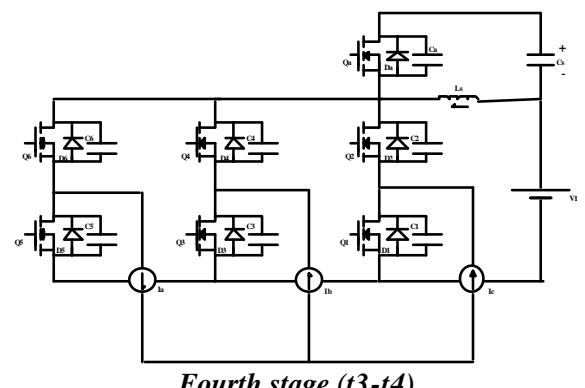

Fourth stage (t3-t4)

$$
\begin{aligned}
& \text { Vout }=127 \mathrm{~V} \\
& \text { Pout }_{3 \phi}=12 \mathrm{kVA}
\end{aligned}
$$

RMS Output Voltage

Output Power
Bus Voltage

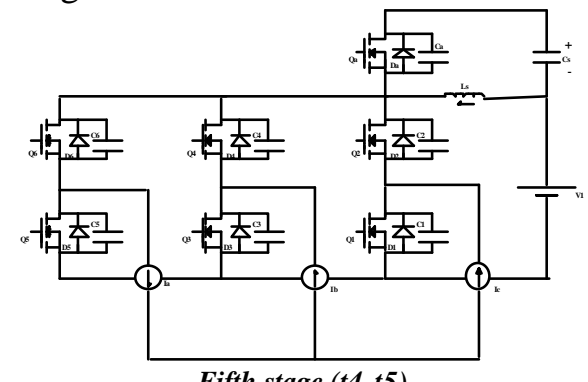

Fifth stage (t4-t5)
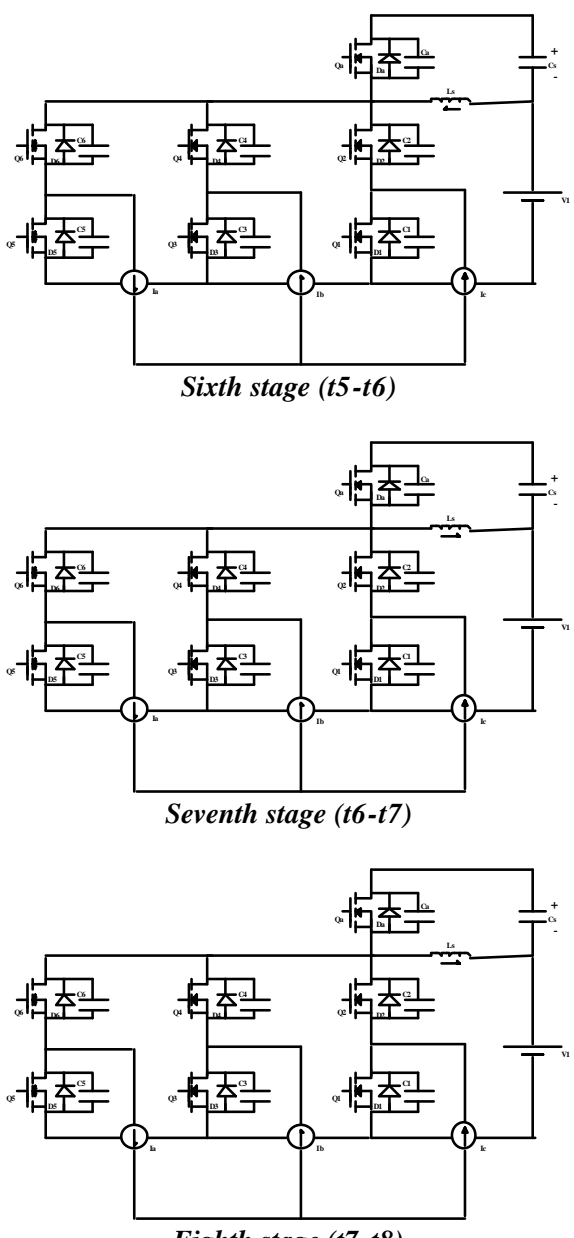

Eighth stage (t7-t8)

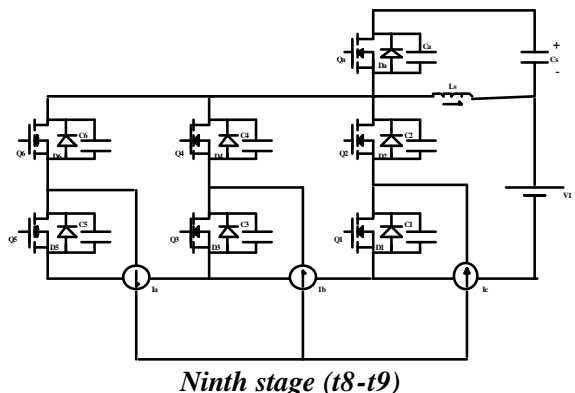

Ninth stage (t8-t9)
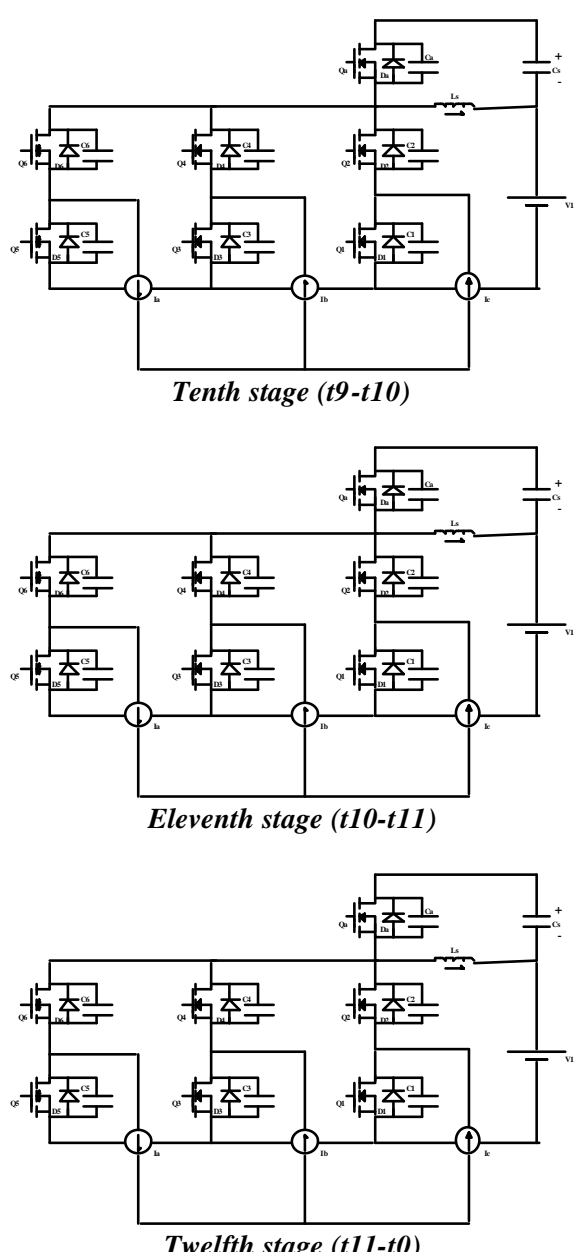

Fig. 2. Operation Stage.

$\mathrm{fs}=20 \mathrm{KHz}$

$\mathrm{f}=60 \mathrm{~Hz}$

$\mathrm{Lca}=\mathrm{Lcb}=\mathrm{Lcc}=575 \mu \mathrm{H}$

$\mathrm{Rca}=\mathrm{Rcb}=\mathrm{Rcc}=4 \Omega$
Switching Frequency

Output Frequency

Load Inductance

Load Resistance $\mathrm{ma}=0,9$

Modulation Factor

\subsection{Calculation of the Auxiliary Inductor}


The auxiliary inductor is responsible for the $\mathrm{di} / \mathrm{dt}$ limit during the turn off of the main diodes. The di/dt is directly related with the peak reverse recovery current Ir of the anti-parallel diodes. A "snappy" di/dt produces a large amplitude voltage transient and contributes significantly to Electro-magnetic interference.

In the design procedure it is chosen a di/dt that is usually find in the diode data book. This is a simple way to obtain the diodes fundamental parameter for the design of the inverter. In such case the di/dt chosen for this example was 40A/us. Knowing that the current ramp rate is determined by the external circuit, thus:

$$
L s=\frac{E}{d i / d t}=\frac{400 \mathrm{~V}}{40 \mathrm{~A} / \mu s}=10 \mu \mathrm{H}
$$

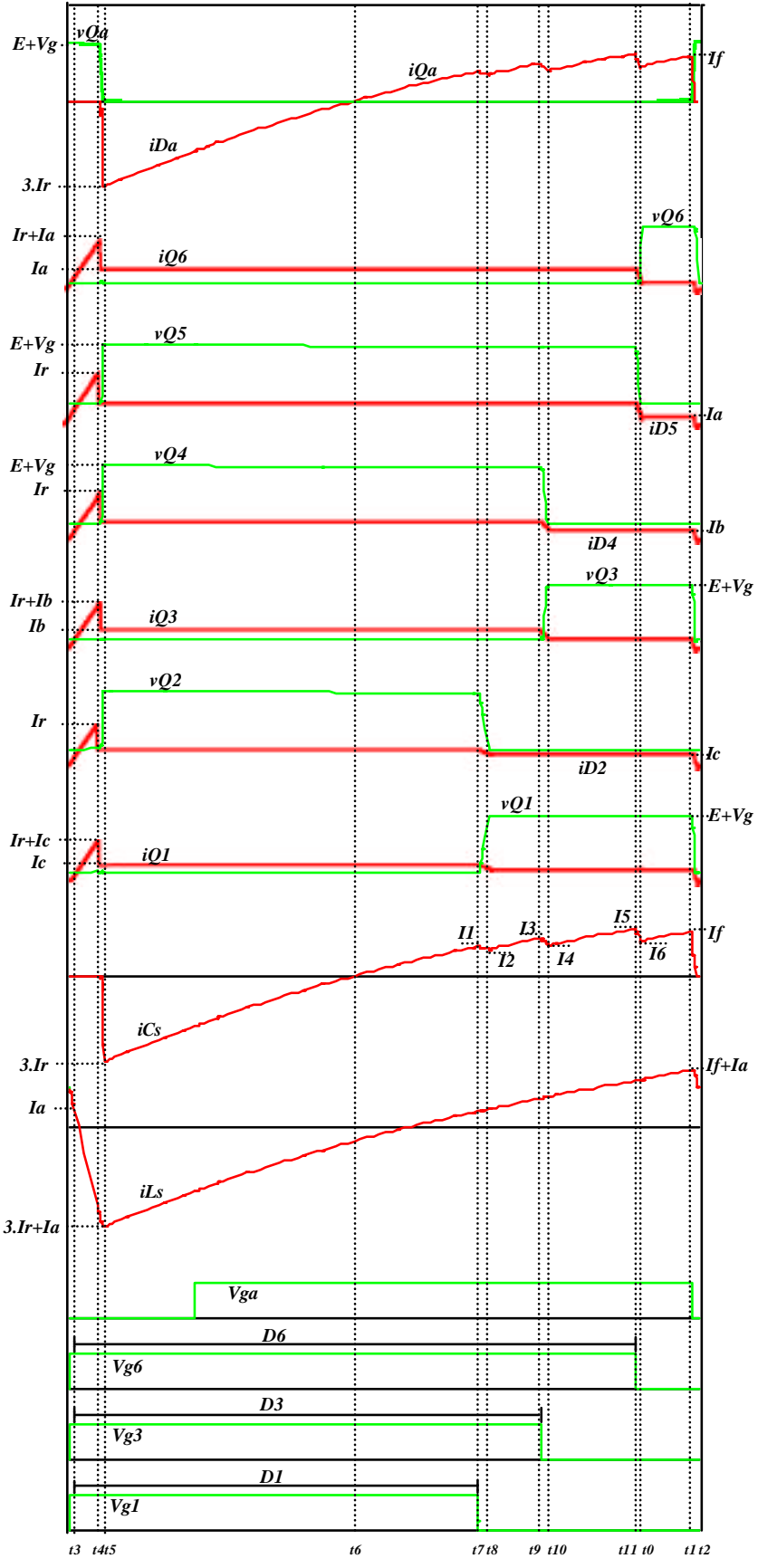

Fig. 3. Main waveforms.

\subsection{Load Impedance}

The load impedance is obtained from Eq. 18.

Zout $=\sqrt{4 \Omega^{2}+(2 \cdot \pi \cdot 60 H z \cdot 575 m H)^{2}} \cong 4 \Omega$

\subsection{Diode Choose}

For the performance of the inverter it is important 
to choose a slow diode. So, we opt to use the diode

SEMIKRON SKKD 81/12, which has the following characteristics:

Vrrm $=1.200 \mathrm{~V}$ Maximum Reverse Voltage

Ifav $=80 \mathrm{~A} \quad$ Diode Average Current

Qrr $=120 \mu \mathrm{C} \quad$ Reverse Recovery Charge

\subsection{Switching Period}

$T s=\frac{1}{f s}=\frac{1}{20 \mathrm{KHz}}=50 \mu \mathrm{s}$

\subsection{Reverse Recovery Current}

The reverse recovery current is given by the Eq. 20 .

$I r=\sqrt{\frac{4}{3} \cdot 120 \mu \mathrm{C} \cdot \frac{400 \mathrm{~V}}{10 \mu \mathrm{H}}}=80 \mathrm{~A}$

\subsection{Capacitor Clamping Voltage Behavior}

Using a Eq. 13 the curves described in Fig. 4 are obtained.

For ma $=0,9$, the maximum clamping voltage is 108V. We can observe that the voltage increment across the switches is too low.

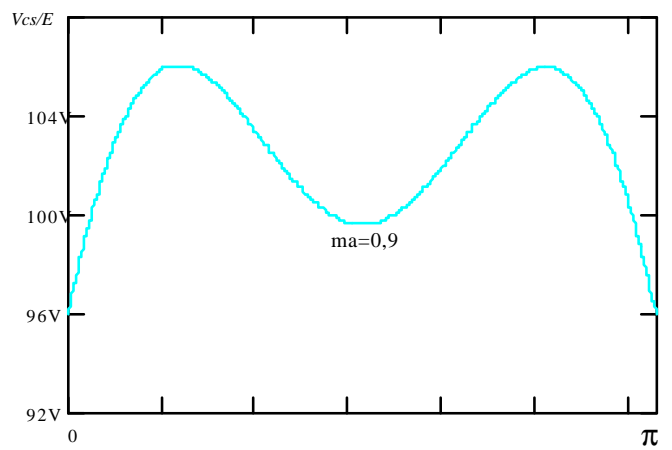

Fig 4. Capacitor Clamping Voltage Behavior.

\subsection{Current If Behavior}

The current If behavior, obtained from Eq. 2 and Eq.16, can be seen in Fig. 5 .

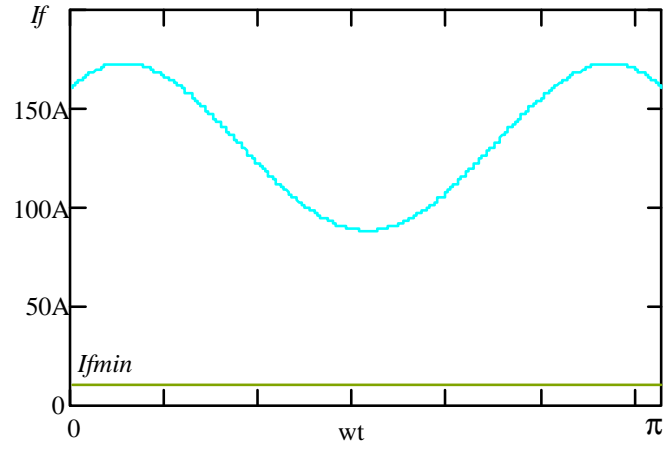

Fig. 5. Current If Behavior.

It is observed that the current If has a minimum point that is bcated in $\pi / 2$, and the intensity of the current diminishes with the increase of the load. To guarantee ZVS condition in all range load, the minimum value of the current If, obtained from Eq. 16, must be bigger than the value of the traced straight line from Eq. 2.

\section{Experimental Results}

An inverter prototype rated $12 \mathrm{kVA}$ operating with PWM commutation was built to evaluate the proposed circuit. The main specifications and components are given below:

\subsection{Prototype Specifications}

$\begin{array}{ll}\text { Pout }_{3 \phi}=12 \mathrm{kVA} & \text { (Output Power) } \\ \mathrm{E}=400 \mathrm{~V} & \text { (Input Voltage) } \\ \text { Vout }=127 \mathrm{~V} & \text { (Rms Output Voltage) } \\ \mathrm{f}=60 \mathrm{~Hz} & \text { (Output Frequency) } \\ \mathrm{fs}=20 \mathrm{kHz} & \text { (Switching Frequency) } \\ \text { Switches } & \text { (IGBT GA250TS60U) } \\ \text { Diodes } & \text { (SKKD81/12) } \\ \text { Intrinsic Capacitance } & 1.5 \mathrm{nF} \\ \text { Ls } & \text { (10uH each; Ferrite Core } \\ \text { EE55/39; N=20 turns, 57 wires \#22AWG) }\end{array}$

Cs

(4 x 1000uF/350V; Electro-

lytic Capacitor)

\subsection{Experimental Waveforms}

In the figures presented in this paragraph we can observe the experimental waveforms obtained from the laboratory prototype. Figs. 6, 7 and 8 show the voltage 
and current in the switches. In Fig. 9 it can be dbserved the current in the commutation auxiliary inductor for a switching period. The voltage across the clamping capacitor $\mathbf{C s}$ is shown in Fig. 10. We can note a very low voltage across Cs. The output voltage and current are presented in Fig. 11. The efficiency of the converter at full load was about $96.5 \%$.

\section{Conclusion}

A ZVS PWM Three-Phase Inverter with voltage clamping using a single auxiliary switch has been developed. The operation stages for steady-state condition, mathematical analysis, main waveforms and experimental results were presented. The experimental results show a low voltage in the clamping capacitor. Conduction and switching losses are reduced due to the implementation of the simple active snubber circuit, which provides ZVS conditions for all the switches, including the auxiliary one. The reduced number of components and the simplicity of the structure increase its efficiency and reliability, and make it suitable for practical applications. The proposed circuit presents soft commutation for all load range, confirming the theoretical studies.

\section{References}

[1] G. Bingen, High Current and Voltage Transistor Utilization, Proceedings of First European Conference on Power Electronics and Applications, 1985, pp. 1.15-1.20.

[2] W. McMurray, Resonant Snubbers with Auxiliary Switches, Conference Records of IEEE IAS Annual Meeting, 1990, pp.829-834.

[3] R. W. De Doncker \& J. P. Lyons, The Auxiliary Resonant Commuted Pole Converter, Conference Records of IEEE IAS Annual Meeting, 1990, pp. 1228-1235.

[4] J. A. Bassett, New Zero Voltage Switching, High Frequency Boost Converter Topology for Power Factor Correction, INTELELEC'95, 1995, pp 813820.

[5] A. Pietkiewicz \& D. Tollik, New High Power Single-Phase Power Factor Corrector with SoftSwitching, INTELEC'96, 1996, pp 114-119. 


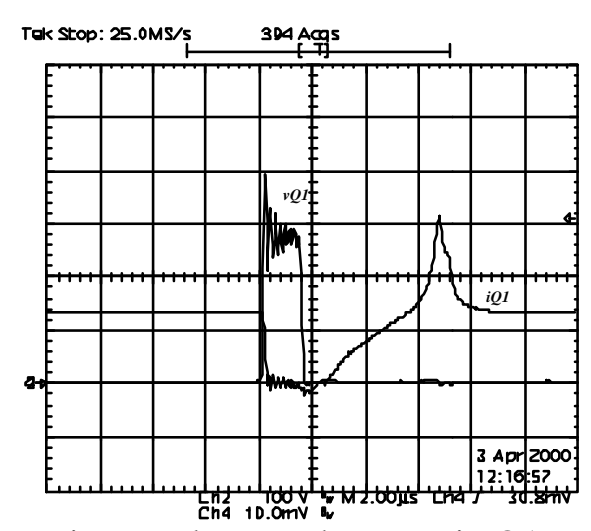

Fig 6. Voltage and current in Q1, $\mathrm{D} 1$, and $\mathrm{C} 1$

100V/div, 20A/div, 2us/div

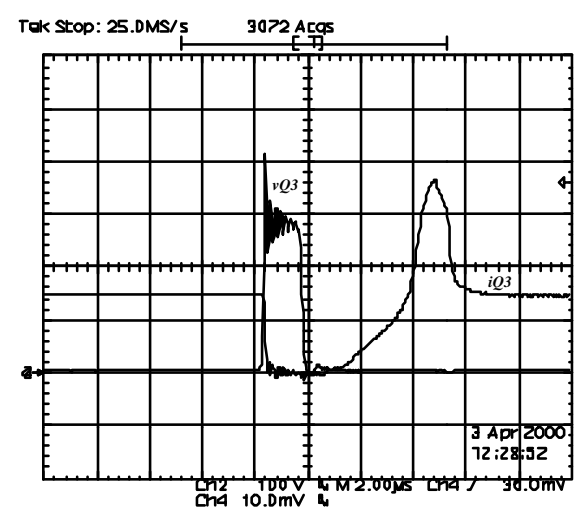

Fig 7. Voltage and current in Q3, D3, and C3

100V/div, 20A/div, 2us/div

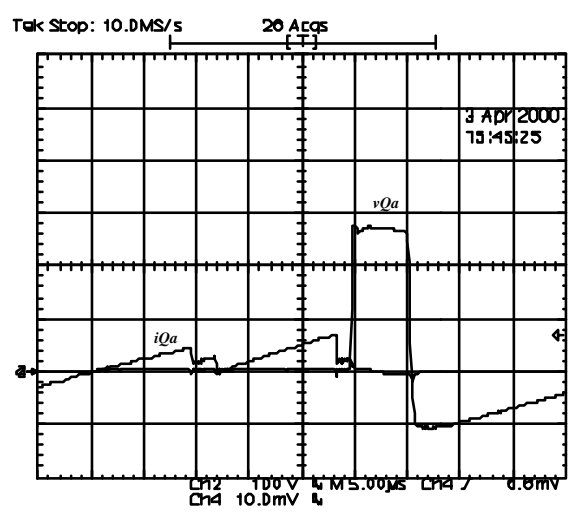

Fig 8. Voltage and current in Qa, $\mathrm{Da}$, and $\mathrm{Ca}$

100V/div, 50A/div, 10us/div

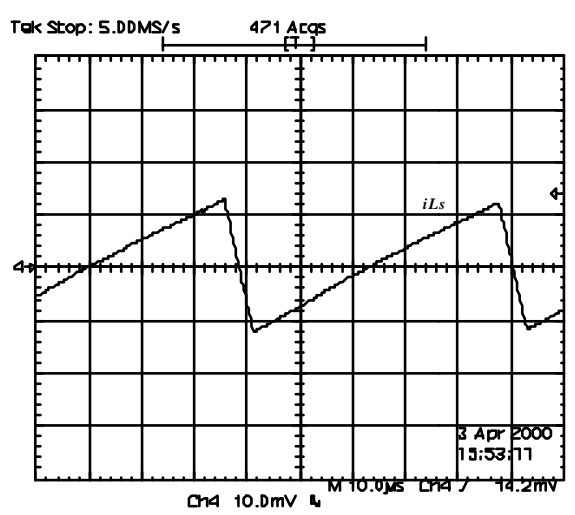

Fig 9. Current in Ls

50A/div, 10us/div

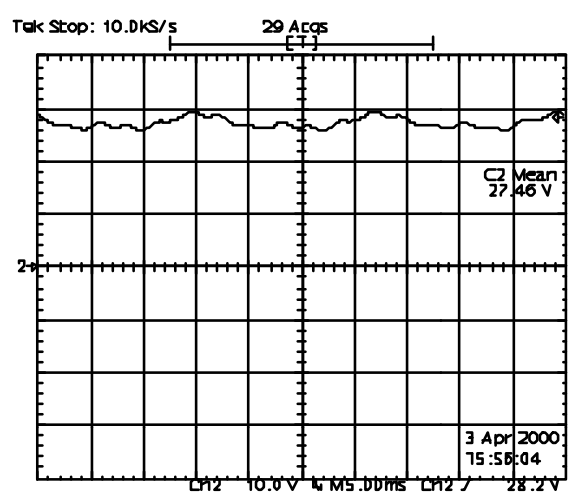

Fig 10. Voltage in Cs

$10 \mathrm{~V} / \mathrm{div}, 5 \mathrm{~ms} / \mathrm{div}$

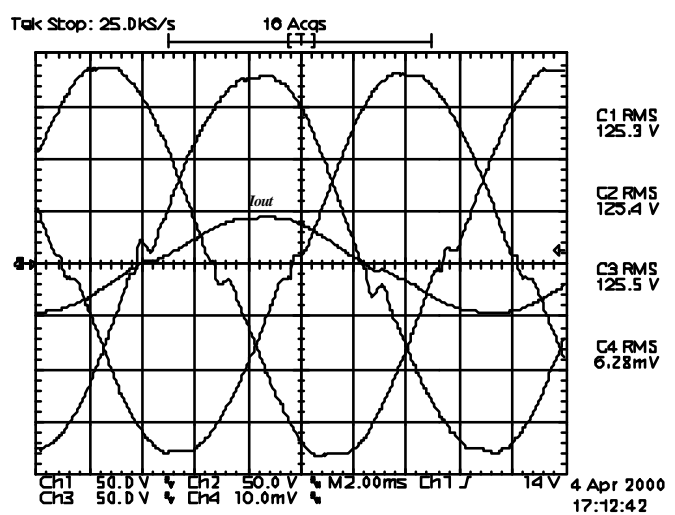

Fig 11. Output voltage and current $50 \mathrm{~V} / \mathrm{div}, 50 \mathrm{~A} / \mathrm{div}, 5 \mathrm{~ms} / \mathrm{div}$

[6] T. M. Underland, Switching Stress Reduction in Power Transistor Convertes. IEEE Industry Applications Society, 1976, pp 383-391.

[7] J. Holtz, S. F. Salama, and K. Werner, A Nondissipative Snubber Circuit for High-Power GTO-Inverters, IEEE Industry Applications, 1987, pp 613-618.

[8] D. Tardiff \& T.H. Barton, A Summary of Resonant Snubbers Circuits for Transistors and GTOS, IEEE PESC, 1989, pp. 1176-1180.

[9] H.G. Langer, G. Fregien, and H.C. Skudelny, A Low Loss Turn-on Turn-off Snubber for GTO-Inverters, IEEE PESC, 1987, pp. 607-612.

[10] A. Cheriti, A Rugged Soft Commutated PWM Inverter for AC Drivers, IEEE PESC, 1990, pp. 656662. 